\title{
Fabrication, Morphology and Cure Behavior of Triethylenetetramine-Grafted Multiwalled Carbon Nanotube/Epoxy Nanocomposites
}

\author{
By Kai YANG* and Mingyuan GU
}

\begin{abstract}
Multiwalled carbon nanotubes (MWCNTs) were first treated by a 3:1 (v/v) mixture of concentrated $\mathrm{H}_{2} \mathrm{SO}_{4} / \mathrm{HNO}_{3}$, and then triethylenetetramine (TETA) grafting was carried out. X-Ray photoelectron spectroscopy and Raman spectroscopy analyses proved the effectiveness of this kind of chemical functionalization method. The TETA thin layer was formed on the MWCNT surface, which contributes to good dispersion of MWCNTs in epoxy matrix. Cure behaviors of MWCNT/epoxy systems were studied with non-isothermal differential scanning calorimetry. MWCNTs have the retarding effect on the cure reaction owing to their steric hindrance, while TETA functional groups on the MWCNT surface can accelerate the primary amineepoxide reaction and weaken the inhibition effect on the process of cure. A qualitative analysis of the degree of vitrification in different epoxy systems was performed. The activation energy of the cure reactions was obtained by the Flynn-Wall-Ozawa method.

KEY WORDS: Carbon Nanotubes / Polymer-Matrix Composites (PMCs) / Cure Behavior / Differential Scanning Calorimetry (DSC) /

Surface Treatments /
\end{abstract}

Carbon nanotubes (CNTs) have stimulated intense research interest since the landmark paper by Iijima, ${ }^{1}$ largely because of their potential applications in diverse fields of nanoscience and nanotechnology, ${ }^{2-4}$ unique structure and superior physical properties such as high Young's modulus, excellent electrical and thermal conductivities, low density, high surface area and high chemical stability. ${ }^{5-7}$ Recently, CNT/polymer composites have been regarded as an extremely promising research topic in the field of material science. Subsequently, extensive researches have been focused on the use of CNTs as nano-fillers to produce a variety of high-performance polymer composites for targeted applications. CNT/polymer composites, including matrices such as polyethylene, ${ }^{8}$ poly (methyl methacrylate) ${ }^{9}$ polypropylene, ${ }^{10}$ polystyrene, ${ }^{11,12}$ nylon ${ }^{13,14}$ and polyamide, ${ }^{15}$ have been studied. The filling of CNTs brings forth very remarkable improvement of the various properties of polymer systems (such as the mechanical, electrical and thermal properties, etc.). ${ }^{16-19}$ Thereby, it is probable to manufacture novel composites by means of combining the complementary properties of CNTs and polymers.

In order to make an optimum use of $\mathrm{CNT} /$ polymer composites, we should understand the nature of their curing process and the structure of the cured material. Especially, the study of the cure reactions of polymer composites as a function of the processing conditions is extremely critical for the analysis and design of processing operations. The final properties of CNT/polymer composites depend significantly on the curing conditions. Accordingly, the research of the cure behaviors is conducive to both a better knowledge of process development and an enhancement of the quality of final products related to the structures of the polymer composites. ${ }^{20}$
Epoxy resins are especially interesting owing to their high modulus, low shrinkage in cure, high adhesion, good chemical and corrosion resistance. ${ }^{21}$ Combining the properties of epoxy with CNTs can supply more extensive applications. Consequently, it is highly worthy to study the cure behaviors of this type of polymer composites. Although there are some studies on the cure reactions of $\mathrm{CNT} /$ polymer systems, ${ }^{22-24}$ the influence of CNTs on the cure behaviors has not been clearly and in depth addressed in the literature yet. In order to obtain superior physical properties of CNT/polymer composites, we need to purify CNTs to get ride of various impurities. Chemical modification not only contributes to the purification process, but also facilitates better dispersion of CNTs in polymer matrix. More specially, some functional groups can be generated on the surface of CNTs through chemical modification. These functional groups have an impact upon the structures and performances of CNT/polymer composites.

In the present work, an effective route to synthesize chemically functionalized MWCNT/epoxy composites is proposed. In this functionalization process, grafting triethylenetetramine (TETA) on the multiwalled CNT (MWCNT) surface can bridge the connection of MWCNTs to the epoxy matrix. The presence of chemically bonded TETA transforms the smooth and nonreactive surface of MWCNTs into a hybrid material that has the characteristics of both MWCNTs and TETA, which will be conducive to the performance of MWCNT/epoxy composites. We used dynamic differential scanning calorimetry (DSC) to investigate the cure behaviors of MWCNT/bisphenol-A glycidol ether epoxy resin (DGEBA)/2-ethyl-4-methylimidazole (EMI-2,4) composites and analyze the effects of MWCNTs and chemical functionalization on the curing process. 


\section{EXPERIMENTAL}

\section{Materials}

Epoxy resin utilized in this work was a nominally difunctional epoxy resin, Epon 828 supplied by Shanghai Resin Co. Epon 828 is, basically, DGEBA with the epoxy value of $0.48-$ $0.52 \mathrm{~mol} / 100 \mathrm{~g}$ and its structure is described by Zhou. ${ }^{25}$ The curing agent, EMI-2,4, was provided by Beijing Chemical Reagent Co. Imidazole is a type of nucleophilic hardener. The net epoxy cured by it possesses better heat endurance, higher modulus and wider curing temperature range than that cured by amine curing agents. In this work, EMI-2,4 has excellent compatibility with DGEBA. The cure temperature of DGEBA/ EMI-2,4 system is relatively low and its gel time is long. In the meantime, the final cured product has high heat deformation temperature, good heat durability, superior chemical stability and mechanical properties. Therefore, we used EMI-2,4 to achieve the cure of epoxy. MWCNTs were obtained from the Nanotech Port Company, Shenzhen, China. These MWCNTs were produced by chemical vapor deposition (CVD). This kind of catalytic production is simple and has a high productivity. The external diameter and the length of MWCNTs are 60$100 \mathrm{~nm}$ and 5-15 $\mu \mathrm{m}$, respectively.

\section{Chemical Functionalization of MWCNTs}

The synthetic procedure is revealed in Figure 1. MWCNTs were first treated by a $3: 1(\mathrm{v} / \mathrm{v})$ mixture of concentrated $\mathrm{H}_{2} \mathrm{SO}_{4} / \mathrm{HNO}_{3}$, with sonication at $40^{\circ} \mathrm{C}$ for $10 \mathrm{~h}$. After acid treatment, MWCNTs were washed using deionized water, filtered until the $\mathrm{pH}$ value reached 7 and dried at $80^{\circ} \mathrm{C}$ for $24 \mathrm{~h}$. The acid-treated MWCNT (MWCNT-COOH) was reacted with excess $\mathrm{SOCl}_{2}$ for $24 \mathrm{~h}$ under reflux to yield acyl chloridefunctionalized MWCNT (MWCNT-COCl). The MWCNT$\mathrm{COCl}$ was further reacted with TETA at $120^{\circ} \mathrm{C}$ under magnetic stirring for $96 \mathrm{~h}$ to produce MWCNT-TETA.

\section{Preparation of MWCNT/Epoxy Nanocomposites}

In order to check the wetting of MWCNT-TETA in organic solvent, such as chloroform, it was dispersed in chloroform and wait for $72 \mathrm{~h}$. MWCNT/epoxy composites were prepared in solution blended method, namely, using chloroform as the cosolvent. Unmodified or modified MWCNTs were dispersed separately in chloroform and sonicated for $1 \mathrm{~h}$. The dispersion was mixed with DGEBA. The mixture was sonicated and stirred for homogenization at $60^{\circ} \mathrm{C}$. This treatment increased the viscosity of the dispersion, which in turn limited the MWCNT aggregation. Subsequently, the mixture was treated by a post heating at $90{ }^{\circ} \mathrm{C}$ in order to completely remove the solvent. And then, the mixture was kept in a vacuum oven for $24 \mathrm{~h}$ to get rid of air bubbles. Subsequently, the curing agent was added to the mixture, which was stirred by using a magnetic bar for $30 \mathrm{~min}$ under sonication. Finally, the mixture was poured into a mould and the whole system was placed in an oven. The MWCNT/ epoxy compound was precured at $70^{\circ} \mathrm{C}$ for $1 \mathrm{~h}$, cured at $110^{\circ} \mathrm{C}$ for $1.5 \mathrm{~h}$ and postcured at $140^{\circ} \mathrm{C}$ for $1.5 \mathrm{~h}$.
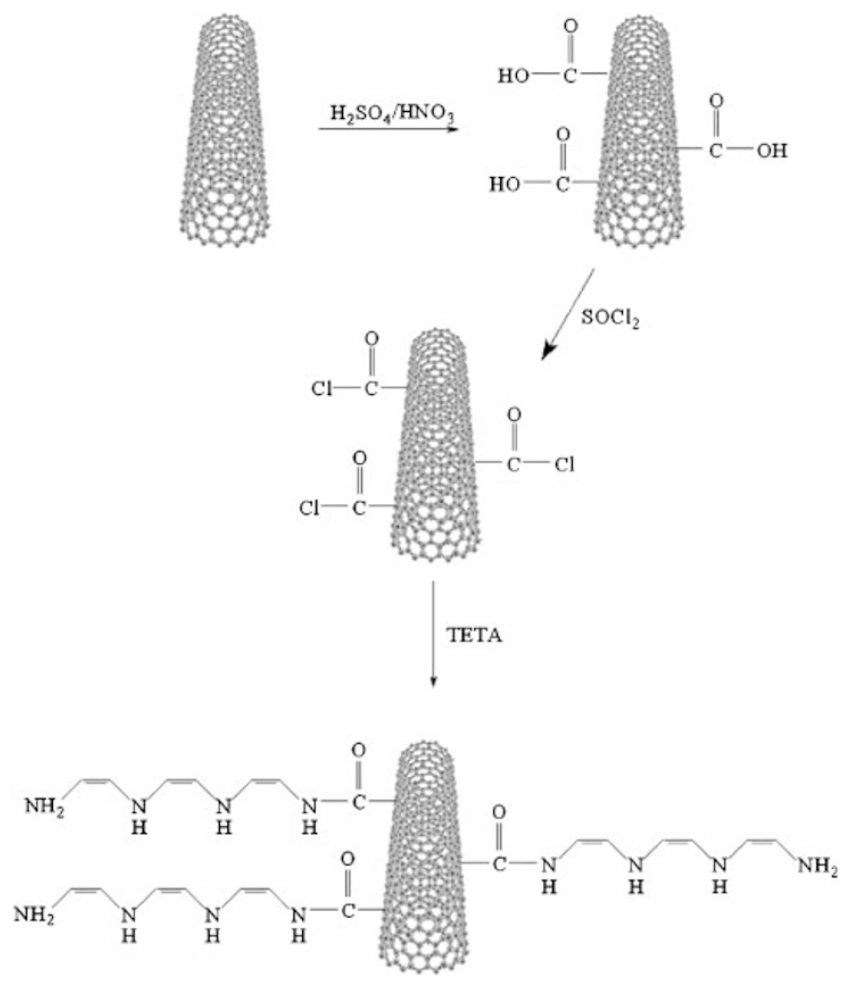

Figure 1. Scheme for the process of grafting TETA onto the MWCNT surface.

\section{Instrumental Analysis}

X-Ray photoelectron spectroscopy (XPS) analysis was performed in an ultra high vacuum system equipped with a Kratos AXIS Ultra hemispherical electron analyzer, using a monochromated $\mathrm{Al} \mathrm{K} \alpha$ source $(1486.6 \mathrm{eV})$, at a base pressure of $2 \times 10^{-10}$ mbar. Charging effects were compensated by a flood gun, and binding energies were calibrated using the main C 1s peak at $284.6 \mathrm{eV}$ as internal standard. Raman spectra were obtained using a Renishaw RM3000 Raman microscope equipped with a 1800 lines/mm grating and a motorized three-axis XYZ mapping stage. A $514.5 \mathrm{~nm}$ excitation line of an argon laser was used, while the laser power, measured directly on the specimen, was $\sim 10 \mathrm{~mW}$. High-resolution transmission electron microscopy (HRTEM) images were taken on JEM $2100 \mathrm{~F}$ to characterize the microstructures of MWCNTs. The morphological observations were carried out with a field emission scanning electron microscope (FESEM) (FEI SIRION 200, USA). The specimens were prepared by mixing DGEBA, EMI-2,4 and unmodified or chemically modified MWCNTs (their weight ratios are displayed in Table I). Then, the mixtures were sonicated and subsequently homogenized by magnetic stirring for $2 \mathrm{~h}$ to break down the agglomerations of MWCNTs. Approximately $5 \mathrm{mg}$ sample of the mixture was weighed accurately into an aluminum DSC sample pan and then covered with an aluminum lid. Thermal analysis was carried out by non-isothermal DSC using a Perkin-Elmer DSC-7 system. The specimens were scanned at three different heating rates of 10,15 and $20 \mathrm{~K} \cdot \mathrm{min}^{-1}$ under a constant flow of nitrogen at $50 \mathrm{~mL} \cdot \mathrm{min}^{-1}$. 

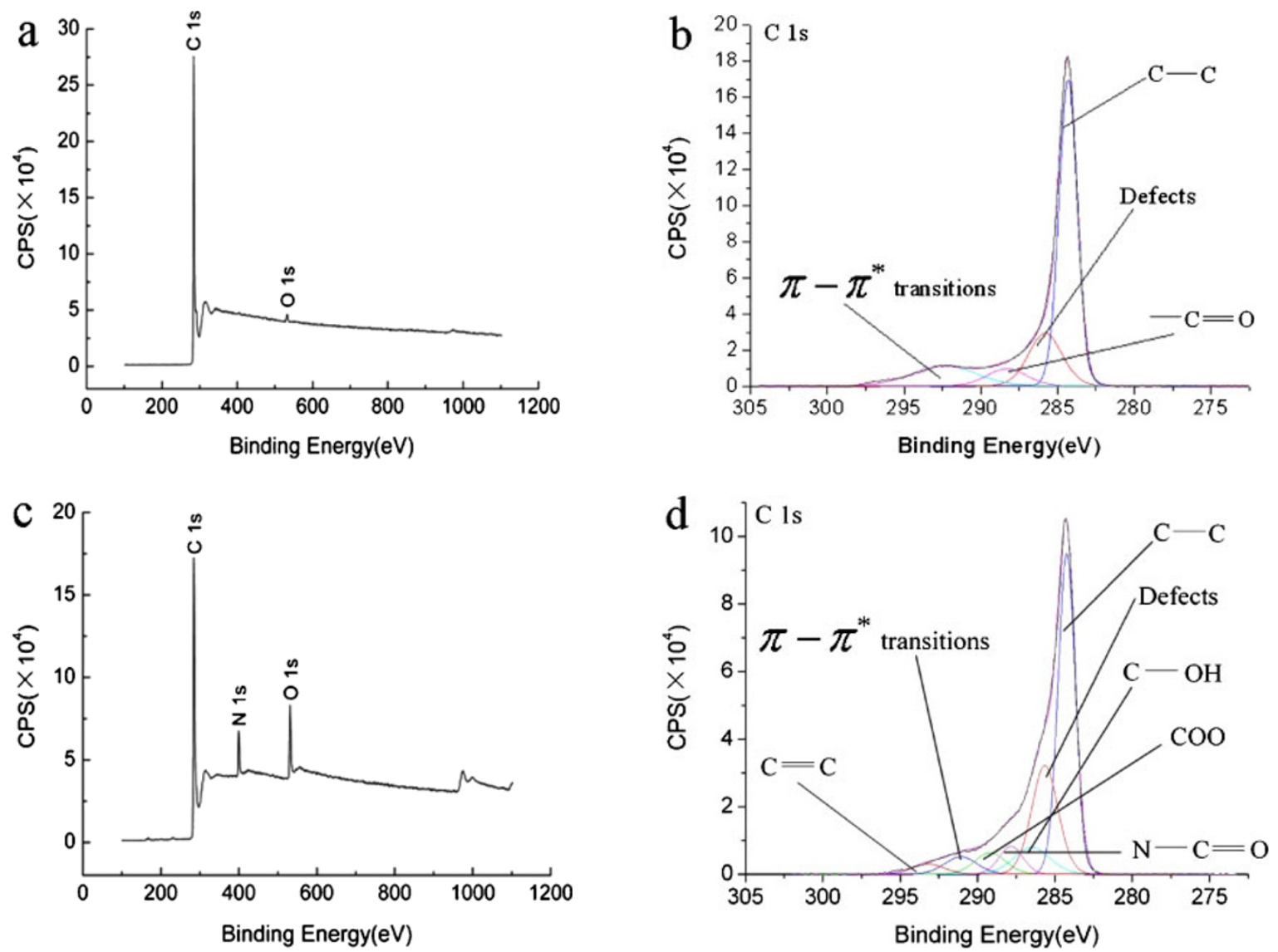

Figure 2. XPS spectra of (a,b) as-received MWCNTs and (c,d) TETA-grafted MWCNTs.

Table I. Compositions of the specimens (by weight)

\begin{tabular}{cccl}
\hline Systems & DGEBA & EMI-2,4 & \multicolumn{1}{c}{ MWCNTs } \\
\hline $\mathrm{S}_{1}$ & 100 & 6 & 0 \\
$\mathrm{~S}_{2}$ & 100 & 6 & 1 (as-received MWCNTs) \\
$\mathrm{S}_{3}$ & 100 & 6 & 1 (TETA-grafted MWCNTs) \\
\hline
\end{tabular}

\section{RESULTS AND DISCUSSION}

\section{Characterization of TETA-grafted MWCNTs}

Figure 2 shows the XPS survey spectra of as-received MWCNTs and TETA-grafted MWCNTs and the deconvolutions of the corresponding $\mathrm{C}$ 1s spectra. All the spectra exhibit $\mathrm{C} 1 \mathrm{~s}$ and $\mathrm{O} 1 \mathrm{~s}$ peaks, whereas the XPS spectrum of TETAgrafted MWCNTs exhibits the remarkable intensification of $\mathrm{O}$ 1s peak. The reason for this phenomenon could be due to the great effect of $\mathrm{H}_{2} \mathrm{SO}_{4} / \mathrm{HNO}_{3}$ treatment on the MWCNT surface. In addition, a N 1s peak is also found in this spectrum, which indicates that TETA has been successfully grafted onto the MWCNT surface (shown in Figure 2(a) and Figure 2(c)). The surface atomic concentration of the two samples is summarized in Table II. The C 1s XPS spectra of the two samples were deconvoluted into separated peaks (presented in Figure 2(b) and Figure 2(d)). Deconvolution of the $\mathrm{C} 1 \mathrm{~s}$
Table II. Atomic percentage of XPS spectra

\begin{tabular}{ccc}
\hline Signal & As-received MWCNTs & TETA-grafted MWCNTs \\
\hline C 1s (\%) & 98.82 & 85.26 \\
O 1s (\%) & 1.18 & 8.02 \\
N 1s (\%) & 0 & 6.72 \\
\hline
\end{tabular}

spectrum of as-received MWCNTs shows a dominant peak at $284.6 \mathrm{eV}$ attributed to the $\mathrm{sp}^{2}$ carbon atoms of the grapheme sheets, a peak at $285.6 \mathrm{eV}$ attributed to defects on the nanotube structure, a peak at $287.9 \mathrm{eV}$ due to $-\mathrm{C}=\mathrm{O}$ bonds ${ }^{26}$ and the $\pi$ $\pi^{*}$ transition loss peak at $291.5 \mathrm{eV} .{ }^{27}$ With respect to TETAgrafted MWCNTs, the two peaks appear at $286.8 \mathrm{eV}$ and $289.0 \mathrm{eV}$, which can be assigned to the $\mathrm{C}-\mathrm{OH}$ bonds of MWCNTs and the COO bonds in carboxylic groups, respectively. The peaks at $287.8 \mathrm{eV}$ and $292.7 \mathrm{eV}$ are respectively attributed to $\mathrm{N}-\mathrm{C}=\mathrm{O}$ bonds and $\mathrm{C}=\mathrm{C}$ bonds. The above analysis presents the effectiveness of chemical functionalization of MWCNTs.

The Raman spectra exhibited in Figure 3 reveal the D and G bands at $1352 \mathrm{~cm}^{-1}$ and $1580 \mathrm{~cm}^{-1}$ for as-received MWCNTs and TETA-grafted MWCNTs, which are derived from disordered graphite structures and concentric cylinders of graphite layers, respectively. Figure $3 \mathrm{~b}$ depicts the D band intensity of TETA-grafted MWCNTs, suggesting that chemical function- 


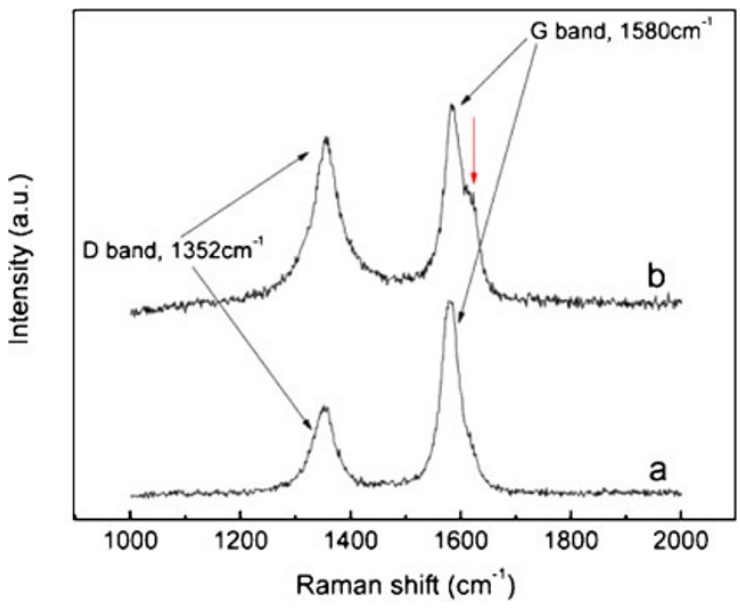

Figure 3. Raman spectra of (a) as-received MWCNTs and (b) TETA-grafted MWCNTs.

alization will increase the $\mathrm{D}$ band intensity. Moreover, a shoulder band located at $1622 \mathrm{~cm}^{-1}$ can be observed for TETA-grafted MWCNTs. This peak has been related to the $\mathrm{sp}^{2}$ hybridization of carbon and is regarded as an evidence of the disruption of the aromatic system of $\mathrm{p}$ electrons by the attached molecules. ${ }^{28,29}$ The obvious shoulder peak at 1622 $\mathrm{cm}^{-1}$ of TETA-grafted MWCNTs as compared to as-received MWCNTs demonstrates a significant content of organic molecules covalently attached.

The microstructures of as-received MWCNT and TETAgrafted MWCNT are shown in Figure 4. It can be seen from Figure 4(a) that the structure of the as-received MWCNT is clear. However, the structure of the TETA-grafted MWCNT is indistinct (presented in Figure 4(c)), which may be due to TETA grafting procedure. In Figure 4(b), the surface of the asreceived MWCNT is smooth. However, the surface of the TETA-grafted MWCNT becomes rough, which is attributed to a TETA layer formed on its tube wall. The clearer structures of the TETA layer and the tube wall of the TETA-grafted MWCNT are revealed in Figure 4(d). Thus HRTEM analysis supplies the direct evidence that TETA is effectively grafted onto the MWCNT wall to form a thin layer.

Figure 5 displays FESEM microphotographs of as-received MWCNTs (Figure 5(a)), acid-treated MWCNTs (Figure 5(b)) and TETA-grafted MWCNTs (Figure 5(c)). It can be observed
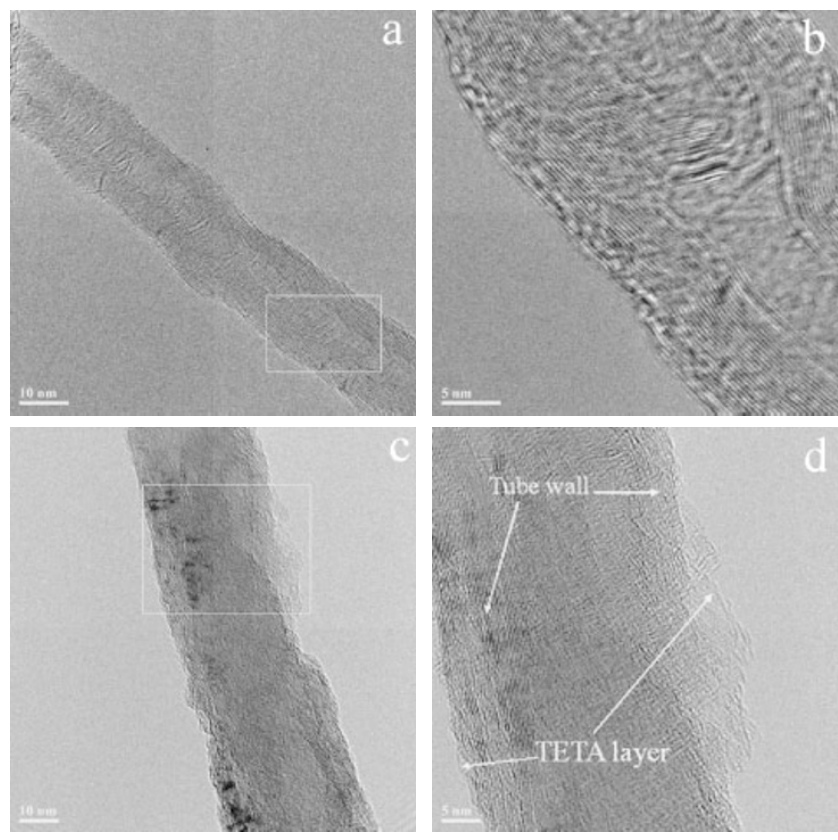

Figure 4. (a) HRTEM image of an as-received MWCNT; (b) Magnification of the position marked with the white square in (a); (c) HRTEM image of a TETA-grafted MWCNT; (d) Magnification of the position marked with the white square in (c).

that as-received MWCNTs are curled and entangled; however, there are few big agglomerates in them. After acid treatment, MWCNTs are severely entangled and form big agglomeration. The interspaces formed in acid-treated MWCNTs are extremely small. While further TETA grafting breaks those big agglomerates and recovers the loose state of MWCNTs. The reasons for the changes in morphology of MWCNTs are analyzed in Figure $6 . \mathrm{H}_{2} \mathrm{SO}_{4} / \mathrm{HNO}_{3}$ treatment would introduce a number of carboxyl and hydroxyl groups onto the MWCNT walls. Acid-treated MWCNTs have large polar forces derived from the strong interactions among these polar groups on their surface. So the interspaces formed in $\mathrm{H}_{2} \mathrm{SO}_{4} / \mathrm{HNO}_{3}$-treated MWCNTs get very small. TETA grafting varies the forces among MWCNTs from polar to nonpolar; In the meantime, TETA molecules may increase the tube-to-tube distances. Accordingly, the interspaces formed in TETA-grafted MWCNTs become large again. Moreover, TETA-grafted MWCNTs are looser than as-received MWCNTs, which is conducive to their better dispersion in epoxy matrix.
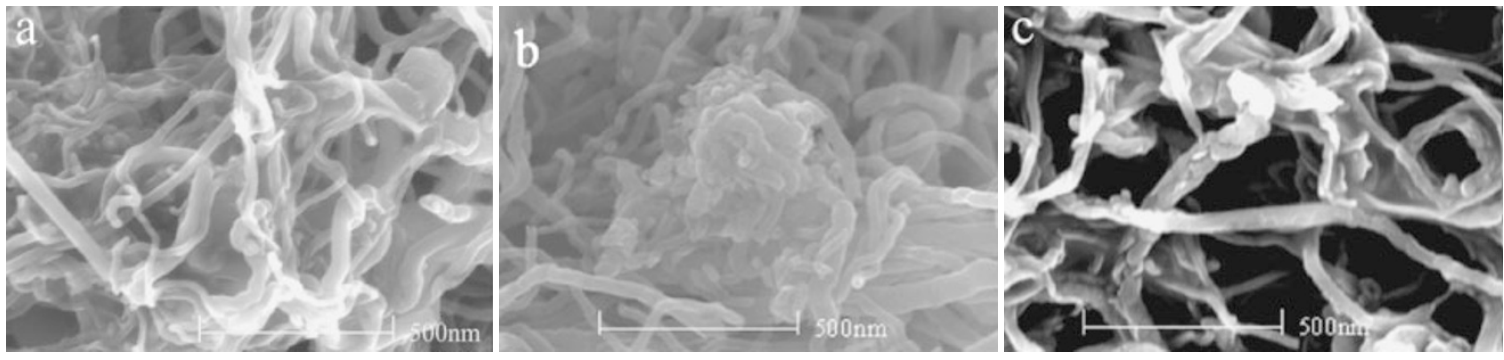

Figure 5. FESEM images of (a) as-received MWCNTs, (b) acid-treated MWCNTs and (c) TETA-grafted MWCNTs. 

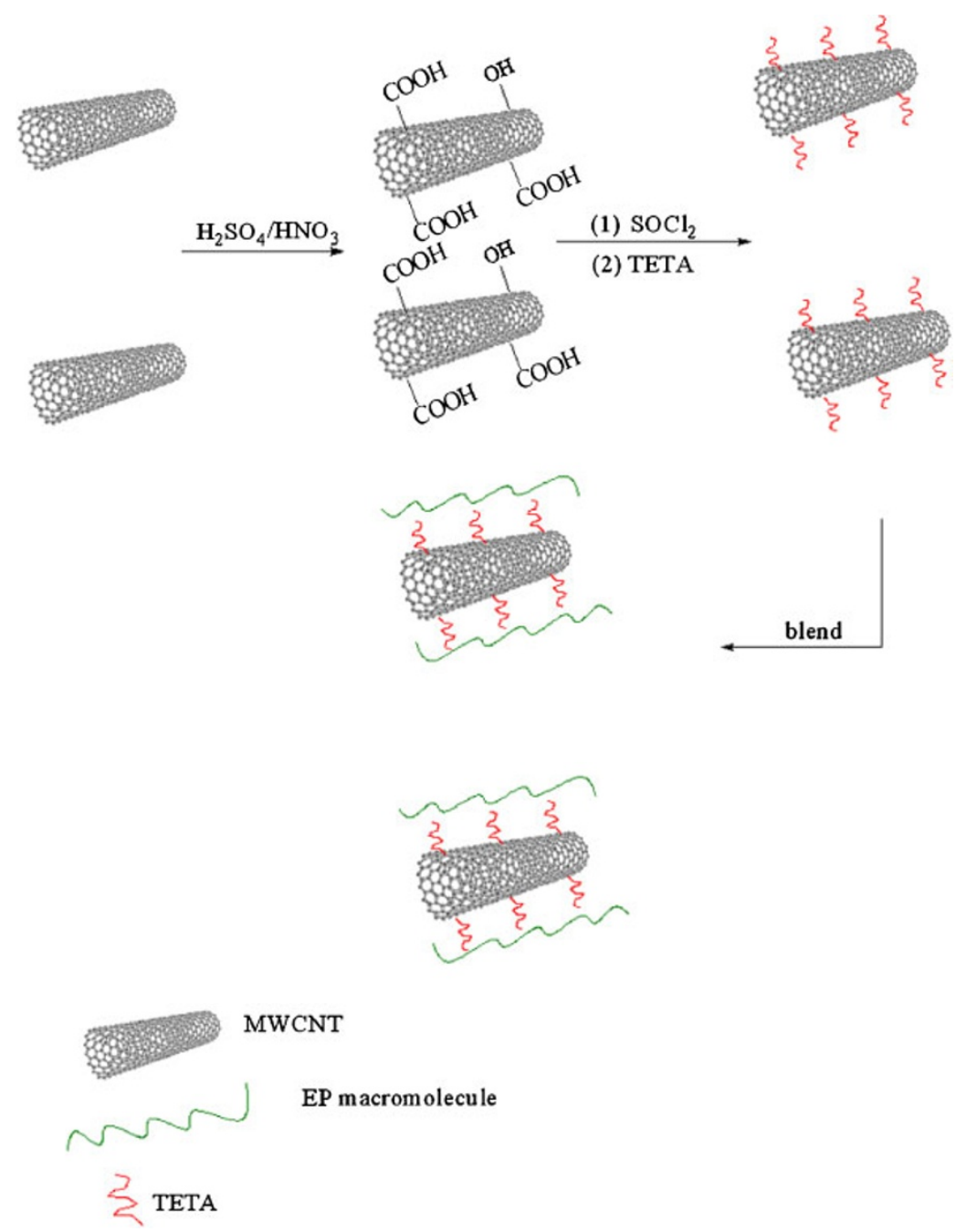

Figure 6. Reasons for varying sized interspaces formed in unmodified and chemically modified MWCNTs.

The functionalized MWCNTs usually present a much better dispersion or higher solubility in solvents. A stable dispersion was obtained in the case of TETA-grafted MWCNTs when equal amounts of as-received MWCNTs and TETA-grafted MWCNTs were respectively added to the same volume of chloroform and mechanically mixed (shown in Figure 7). As shown in Figure 7a, all of nanotubes sank in the case of raw MWCNTs. This indicates that TETA-grafted MWCNTs (Figure 7b) have a higher degree of miscibility than asreceived MWCNTs owing to the presence of TETA functional groups on the MWCNT surface.

\section{Morphology and Cure Behavior of MWCNT/Epoxy Nano- composites}

Figure 8 reveals FESEM images of the fracture surfaces of as-received MWCNT/epoxy composite and TETA-grafted MWCNT/epoxy composite. The white regions in Figure 8(a) represent the aggregated MWCNTs and the region indicated with an arrow is magnified as shown in Figure 8(b) in order to verify existence of the MWCNTs. So as-received MWCNTs dispersed in epoxy matrix exist in the form of agglomerates.

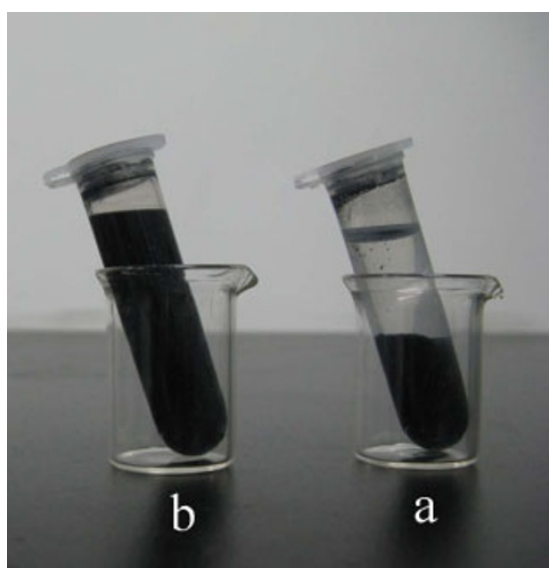

Figure 7. Photograph of (a) as-received MWCNTs and (b) TETA-grafted MWCNTs dispersed in chloroform and wait for $72 \mathrm{~h}$.

On the other hand, Figure 8(c) shows that TETA-grafted MWCNTs are uniformly dispersed in epoxy matrix. This means that TETA grafting would be beneficial to good dispersion of MWCNTs in epoxy resin. 

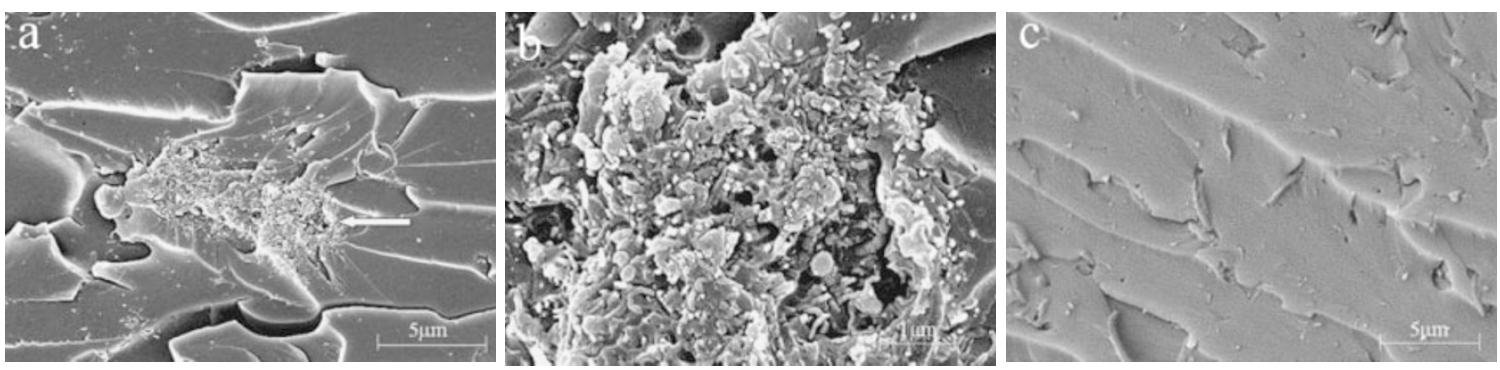

Figure 8. (a) FESEM image of the fracture surface of as-received MWCNT/epoxy composite; (b) Magnification of the position marked with the white arrow in (a); (c) FESEM image of the fracture surface of TETA-grafted MWCNT/epoxy composite. The content of the MWCNTs was $1 \%$ by weight.
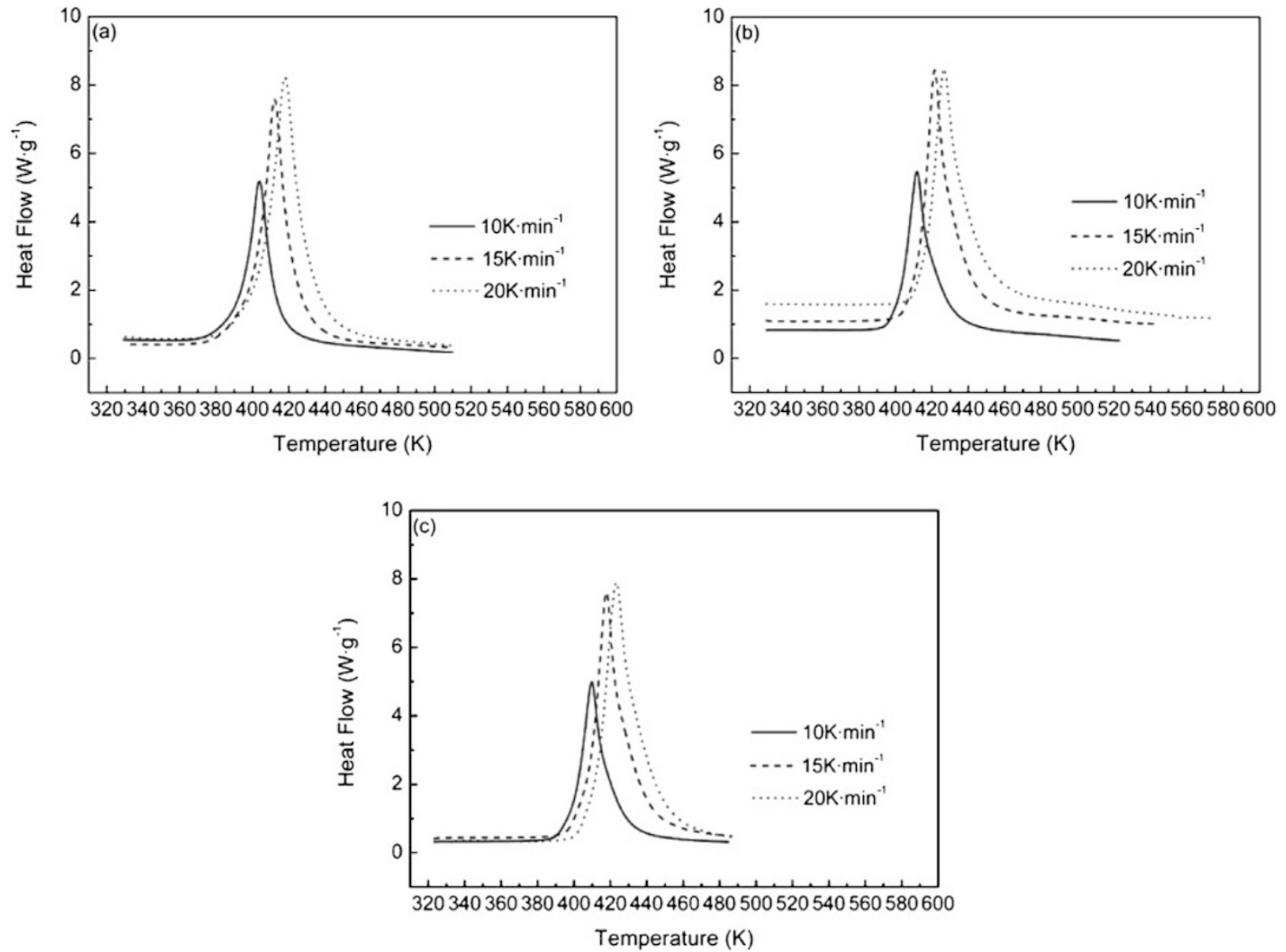

Figure 9. Dynamic DSC thermograms of the different systems. (a) $S_{1}$; (b) $S_{2}$; (c) $S_{3}$.

The curing mechanism of DGEBA/EMI-2,4 system includes two stages consisting of the adduct and etherification reactions. ${ }^{30}$ The adduct reactions were considered to be the catalyst that initiated the etherification reactions which crosslink the epoxy resins and determine their final performance. Previous work presented that the adduct formation was necessary prior to the etherification reactions. Consequently, low EMI-2,4 concentrations can be used to analyze the etherification reactions through suppressing the adduct formation. ${ }^{30}$ In an attempt to objectively meet this specification, the molar heat of the reaction $\Delta H$ should approach a constant. When the concentration of EMI-2,4 is between 3 and 10 wt.- $\%$ (gram mass of EMI-2,4 per $100 \mathrm{~g}$ mass of DGEBA), the variation amplitude of $\Delta H$ is small. However, the cure reaction will be incomplete if the content of EMI-2,4 is below 3 wt.- $\%$. In this work, the concentration of EMI-2,4 is 6 wt.- $\%$ which is in the range of 3-10 wt.-\%. The dynamic DSC thermograms of $\mathrm{S}_{1}, \mathrm{~S}_{2}$ and $\mathrm{S}_{3}$ are illustrated in Figure 9(a)-(c), respectively. As is shown, only a main exothermic peak of the etherification reaction appears. So the heat of reaction for the etherification reaction peak is approximately the total heat of the curing reaction. Additionally, the functional groups on the chemically modified MWCNT surface can act as curing agents to react with the epoxy resin. However, the released heat is much 
Table III. The onset temperature, the peak temperature and the heat of cure in $S_{1}-S_{3}$ systems at the different heating rate

\begin{tabular}{cclll}
\hline & Heating rate $\left(\mathrm{K} \cdot \mathrm{min}^{-1}\right)$ & \multicolumn{1}{c}{10} & \multicolumn{1}{c}{15} & \multicolumn{1}{c}{20} \\
\hline $\mathrm{S}_{1}$ & $T_{\mathrm{i}}(\mathrm{K})$ & 393.6 & 401.4 & 404.8 \\
& $T_{\mathrm{p}}(\mathrm{K})$ & 403.9 & 412.1 & 418.0 \\
& $\Delta H\left(\mathrm{~J} \cdot \mathrm{g}^{-1}\right)$ & 415.50 & 417.97 & 420.48 \\
$\mathrm{~S}_{2}$ & $T_{\mathrm{i}}(\mathrm{K})$ & 404.6 & 412.3 & 415.8 \\
& $T_{\mathrm{p}}(\mathrm{K})$ & 414.6 & 422.4 & 427.8 \\
& $\Delta H\left(\mathrm{~J} \cdot \mathrm{g}^{-1}\right)$ & 403.06 & 406.18 & 409.32 \\
$\mathrm{~S}_{3}$ & $T_{\mathrm{i}}(\mathrm{K})$ & 399.7 & 407.4 & 411.5 \\
& $T_{\mathrm{p}}(\mathrm{K})$ & 409.8 & 417.9 & 423.3 \\
& $\Delta H\left(\mathrm{~J} \cdot \mathrm{g}^{-1}\right)$ & 407.83 & 411.28 & 413.11 \\
\hline
\end{tabular}

smaller than the heat of the curing reaction, which means that it can be negligible. Accordingly, $\Delta H$ can be regarded as a constant over the whole cure reaction. From a dynamic DSC run, the total area $A$ of the exothermal peak (the region between the exotherm and the baseline) is in direct proportion to the molar heat of the reaction $\Delta H$ released during the whole cure reaction. The fraction extent of conversion $\alpha$ at any temperature $T$ can be expressed as: $\alpha=\Delta H_{\mathrm{T}} / \Delta H=A_{\mathrm{T}} / A(0 \leq$ $\alpha \leq 1)$ where $\Delta H_{\mathrm{T}}$ is the heat of reaction of partially cured samples heated up to the temperature $T$. Table III represents the onset temperature $T_{\mathrm{i}}$, the peak temperature $T_{\mathrm{p}}$, and the heat of cure $\Delta H$ of several systems at the different heating rates. With increasing the heating rate, the values of $T_{\mathrm{i}}$ and $T_{\mathrm{p}}$ increase in each system. The reason for $T_{\mathrm{i}}$ and $T_{\mathrm{p}}$ following the sequence $S_{1}<S_{2}$ and $S_{1}<S_{3}$ is the introduction of MWCNTs in the systems, which indicates that MWCNTs delay the cure reaction due to their steric hindrance. ${ }^{23}$ The possible mechanism for MWCNTs to inhibit the cure reaction of epoxy resin system may be the decrease of the propagation reaction speed. With regard to MWCNT/epoxy system, the contents of DGEBA and EMI-2,4 are lower than those in the corresponding unfilled epoxy and viscosity may increase, ${ }^{31}$ which causes decelerating the propagation reaction and extends the gel time of epoxy. Furthermore, the reason for $T_{\mathrm{i}}$ and $T_{\mathrm{p}}$ following the sequence $S_{3}<S_{2}$ may be directly attributed to the role of TETA functional groups on the surface of chemically functionalized MWCNTs. In terms of the curing mechanism for the DGEBA/EMI-2,4 system, ${ }^{30}$ TETA functional groups on the MWCNT surface can play the role of curing agents and facilitate the primary amine-epoxide reaction. Therefore, it can be inferred from the mechanism that these TETA functional groups can enervate the retardation effect on the cure reaction caused by MWCNTs, that is to say, the values of $T_{\mathrm{i}}$ and $T_{\mathrm{p}}$ show a descending tendency. In our systems, the changes of the heating rate have no effect on the total curing reaction heat estimated from the areas under the exothermic peaks of $S_{1}, S_{2}$ and $S_{3}$. Namely, the heat of cure is almost independent of the heating rate. The phenomenon for $\Delta H$ following the sequence $S_{1}>S_{2}$ and $S_{1}>S_{3}$ may be ascribed to the two aspects: the proportional reduction of epoxy in the composites and the retarding effect caused by MWCNTs on the cure reaction. Moreover, $\Delta H$ of $S_{3}$ system was a little higher than that of $S_{2}$ system, which means that the extent of cure was larger in $S_{3}$.

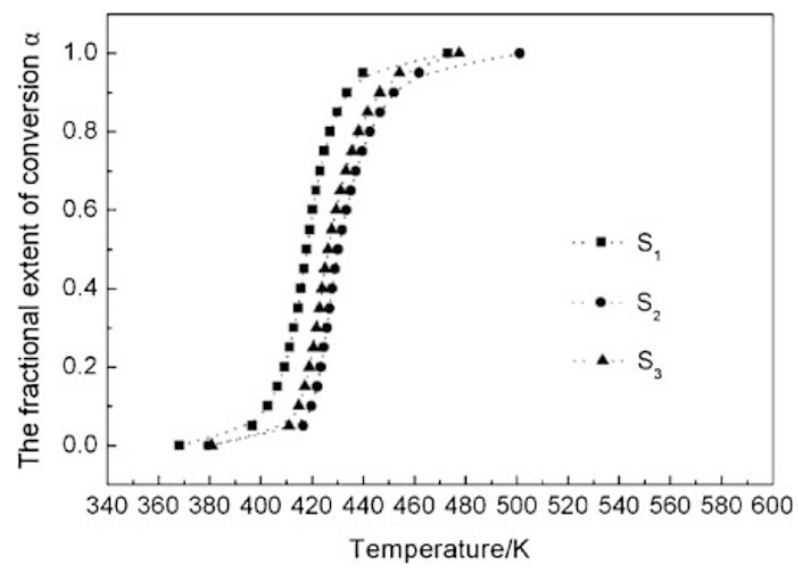

Figure 10. Advancement of the cure reactions for non-isothermal cure at $20 \mathrm{~K} \cdot \mathrm{min}^{-1}$ heating rate of $\mathrm{S}_{1}, \mathrm{~S}_{2}$ and $\mathrm{S}_{3}$ systems. Dotted lines are given only for showing the tendency.

This fact arose from the contributive effect of TETA functional groups on the cure reaction.

Figure 10 presents a comparison of the curing kinetics, at the heating rate of $20 \mathrm{~K} \cdot \mathrm{min}^{-1}$, among $S_{1}, S_{2}$ and $S_{3}$ systems. All curves show a sigmoidal form, which denotes that MWCNT/ epoxy systems have an autocatalytic kinetics. It is known that DGEBA/EMI-2,4 system has autocatalytic kinetics. That is to say, the filling of unmodified and chemically modified MWCNTs does not change the cure mechanism of epoxy resin. In addition, it is obvious that $\mathrm{S}_{2}$ and $\mathrm{S}_{3}$ systems exhibit the characteristic of delayed cure reactions, which indicates that MWCNTs have the retarding effect on the cure reaction of epoxy. The reason for the degree of cure retardation effect following the sequence $S_{3}<S_{2}$ may be directly attributed to the role of TETA functional groups on the chemically functionalized MWCNT surface, namely, accelerating the curing reaction of epoxy. For the development of the composites, the cure inhibition effect caused by MWCNTs could have some negative effects on the composite manufacture since it needs longer postcure time. In addtion, combining Figure 10 with Figure 8, we need to explain a phenomenon. In Figure 8(a), the dispersion of MWCNTs is very poor. However, the curing property of $S_{2}$ is not close to that of $S_{1}$ (shown in Figure 10). It would be natural to think that steric hindrance by MWCNTs during curing in the matrix of $S_{2}$ should be small due to poor dispersion. This seems to be the contradiction. The logical explanation of this phenomenon can be made from the following points: (i) There are many MWCNT agglomerates distributing over the epoxy matrix of $\mathrm{S}_{2}$, so the dispersion of MWCNTs is poor. These micro-size MWCNT agglomerates may still generate the retarding effect on the curing of $S_{2}$. (ii) There might be some interaction between EMI-2,4 and MWCNT surface. EMI-2,4 concentration in and around MWCNT agglomerates might be higher, resulting in that curing property of $S_{2}$ is not similar to that of $S_{1}$.

The fractional extent of conversion $\alpha v s$. temperature $T$ at different heating rates of $S_{1}, S_{2}$ and $S_{3}$ systems is separately reported in Figure 11(a)-(c). It can be seen that for each figure all the curves have the same functional form and only shift a 

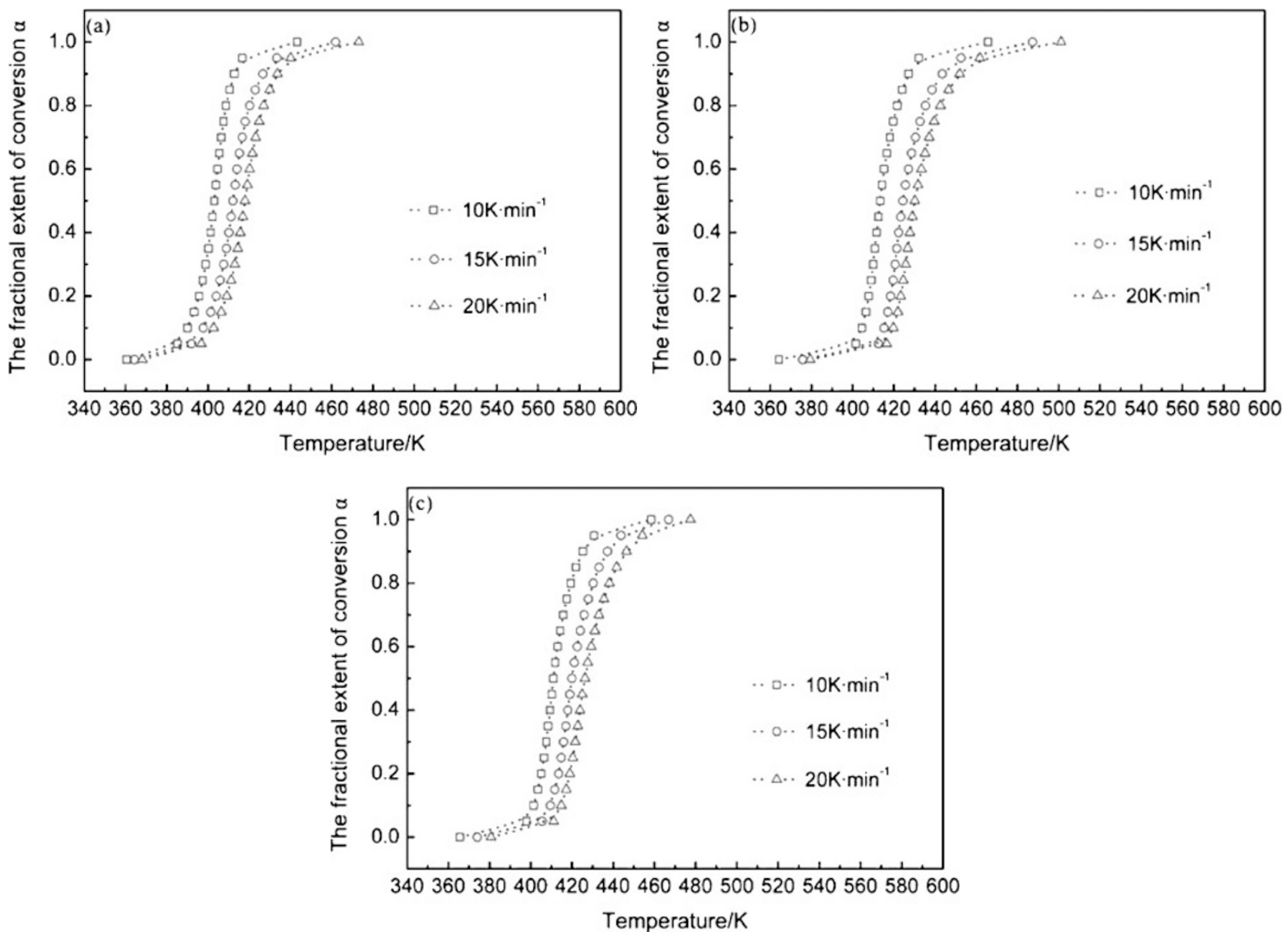

Figure 11. Advancement of the cure reactions for non-isothermal cure at different heating rates of $S_{1}, S_{2}$ and $S_{3}$ systems. Dotted lines are given only for showing the tendency. (a) $S_{1}$; (b) $S_{2}$; (c) $S_{3}$.

distance along the temperature axis. So all the $\alpha$ vs. $T$ curves at different heating rates should be superposable through shifting each curve along the temperature axis relative to a curve at an arbitrary reference heating rate by a shift factor, $\varphi(\beta)=$ $T_{\text {ref }}-T_{\beta}(\alpha=0)$, where $\beta$ is the heating rate. In this work, the curve of $20 \mathrm{~K} \cdot \mathrm{min}^{-1}$ heating rate was considered to be the master curve. The master curve represents the progression of the cure reactions of the materials cured at a reference heating rate. Figure 12(a)-(c) display the superposed curves of $\alpha v s$. $T$ for $S_{1}, S_{2}$ and $S_{3}$ systems.

Kinetic analysis of non-isothermal resin-cured system is based upon the following rate equation: ${ }^{32}$

$$
\frac{\mathrm{d} \alpha}{\mathrm{d} t} \equiv \beta \frac{\mathrm{d} \alpha}{\mathrm{d} T}=k(T) f(\alpha)
$$

where $\beta=\mathrm{d} T / \mathrm{d} t$ is a constant heating rate, $k(T)$ is a temperature-dependent reaction rate constant, and $f(\alpha)$ is the different conversion function depending on the reaction mechanism. In terms of Arrhenius law, $k(T)$ is shown in eq (2):

$$
k(T)=A e^{-E_{\alpha} / R T}
$$

where $\mathrm{A}$ is the pre-exponential factor, $E_{\alpha}$ is the activation energy, and $T$ is the absolute temperature. According to eq (1) and eq (2), $\mathrm{d} \alpha / \mathrm{d} T$ can be expressed as:

$$
\frac{\mathrm{d} \alpha}{\mathrm{d} T}=A e^{-E_{\alpha} / R T} \frac{f(\alpha)}{\beta}
$$

then

$$
\ln \left(\frac{\mathrm{d} \alpha}{\mathrm{d} T}\right)-\ln [A f(\alpha)]=-\frac{E_{\alpha}}{R T}-\ln \beta
$$

In respect of some arbitrary fractional extent of conversion $\alpha$ $(0 \leq \alpha \leq 1)$, the values of $\ln [\operatorname{Af}(\alpha)]$ in the curves at the different heating rates are equal, while the values of $\mathrm{d} \alpha / \mathrm{d} T_{\beta}$, namely, the tangent slope of the point corresponding to the fractional extent conversion $\alpha$ in the curves at the different heating rates, are not always equal to those of $\mathrm{d} \alpha / \mathrm{d} T_{\text {ref }}$ in the reference curve. So there are three possibilities: $\mathrm{d} \alpha / \mathrm{d} T_{\beta}=$ $\mathrm{d} \alpha / \mathrm{d} T_{\text {ref }}, \mathrm{d} \alpha / \mathrm{d} T_{\beta}<\mathrm{d} \alpha / \mathrm{d} T_{\text {ref }}$ or $\mathrm{d} \alpha / \mathrm{d} T_{\beta}>\mathrm{d} \alpha / \mathrm{d} T_{\text {ref. }}$. And then, we can separately analyze the three cases. If the case is $\mathrm{d} \alpha / \mathrm{d} T_{\beta}=\mathrm{d} \alpha / \mathrm{d} T_{\text {ref }}$, from eq (4) we can obtain:

$$
\begin{aligned}
-\frac{E_{\alpha}}{R T_{\beta}}-\ln \beta & =-\frac{E_{\alpha}}{R T_{r e f}}-\ln \beta_{r e f} \\
\frac{1}{T_{\beta}}-\frac{1}{T_{r e f}} & =R\left[\frac{\ln \left(\beta_{r e f} / \beta\right)}{E_{\alpha}}\right]
\end{aligned}
$$



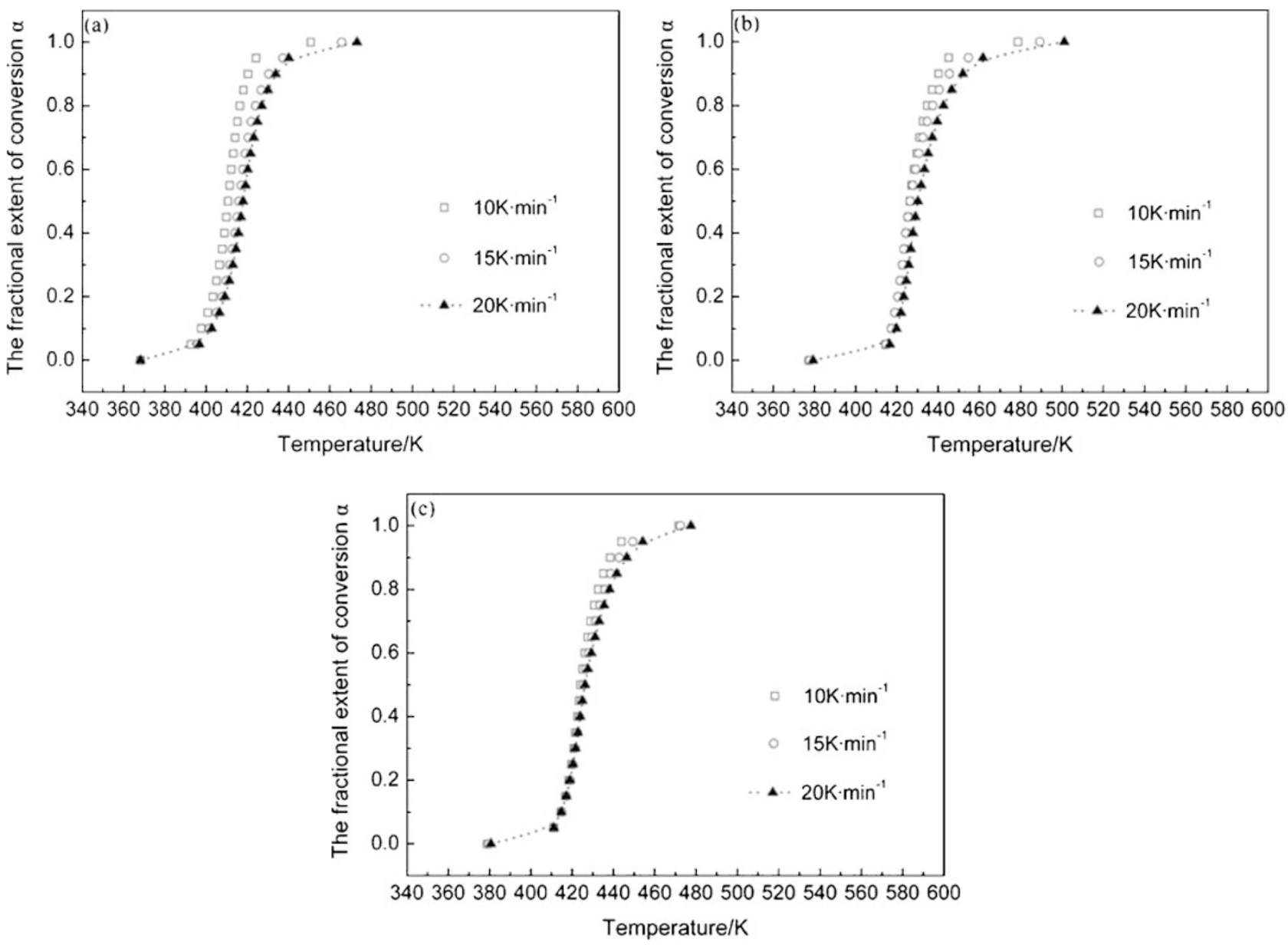

Figure 12. Superposed curves of $\alpha$ vs. $T$ for $S_{1}, S_{2}$ and $S_{3}$ systems. Dotted lines are given only for showing the tendency. (a) $S_{1}$; (b) $S_{2}$; (c) $S_{3}$.

then

$$
T_{r e f}-T_{\beta}=T_{\beta} T_{r e f} R\left[\frac{\ln \left(\beta_{r e f} / \beta\right)}{E_{\alpha}}\right]
$$

The curve of $20 \mathrm{~K} / \mathrm{min}$ heating rate was thought of as the reference curve, thus $\beta_{\text {ref }} / \beta>1$ and $T_{\text {ref }}-T_{\beta}>0$. From Figure 11(a)-(c), it can be observed that $T_{\beta} T_{\text {ref }}$ will increase with increasing $\alpha$. According to eq (7), $T_{\text {ref }}-T_{\beta}$ will increase, which indicates that $\mathrm{d} \alpha / \mathrm{d} T_{\beta}>\mathrm{d} \alpha / \mathrm{d} T_{\text {ref }}$ will happen. However, this case is in contradiction with the previous assumption, that is, $\mathrm{d} \alpha / \mathrm{d} T_{\beta}=\mathrm{d} \alpha / \mathrm{d} T_{\text {ref }}$. Accordingly, the case of $\mathrm{d} \alpha / \mathrm{d} T_{\beta}=$ $\mathrm{d} \alpha / \mathrm{d} T_{\text {ref }}$ is not tenable. Furthermore, we analyze the second case, namely, $\mathrm{d} \alpha / \mathrm{d} T_{\beta}<\mathrm{d} \alpha / \mathrm{d} T_{\text {ref. }}$. Based on it, eq (4) can be changed as follows:

$$
\begin{gathered}
-\frac{E_{\alpha}}{R T_{\beta}}-\ln \beta<-\frac{E_{\alpha}}{R T_{r e f}}-\ln \beta_{r e f} \\
\frac{1}{T_{\beta}}-\frac{1}{T_{r e f}}>R\left[\frac{\ln \left(\beta_{r e f} / \beta\right)}{E_{\alpha}}\right]
\end{gathered}
$$

then

$$
T_{r e f}-T_{\beta}>T_{\beta} T_{r e f} R\left[\frac{\ln \left(\beta_{r e f} / \beta\right)}{E_{\alpha}}\right]
$$

Based upon eq (10), it can be inferred that $T_{\text {ref }}-T_{\beta}$ will augment with the increase of $\alpha$. According to the foregoing discussion, the increase of $T_{\text {ref }}-T_{\beta}$ means that $\mathrm{d} \alpha / \mathrm{d} T_{\beta}>$ $\mathrm{d} \alpha / \mathrm{d} T_{\text {ref }}$ will happen. This point contradicts with the studied second case, namely, $\mathrm{d} \alpha / \mathrm{d} T_{\beta}<\mathrm{d} \alpha / \mathrm{d} T_{\text {ref }}$. So the possibility of $\mathrm{d} \alpha / \mathrm{d} T_{\beta}<\mathrm{d} \alpha / \mathrm{d} T_{\text {ref }}$ is still untenable. Finally, we check the third case: $\mathrm{d} \alpha / \mathrm{d} T_{\beta}>\mathrm{d} \alpha / \mathrm{d} T_{\text {ref. }}$. From eq (4) we can obtain:

$$
\begin{gathered}
-\frac{E_{\alpha}}{R T_{\beta}}-\ln \beta>-\frac{E_{\alpha}}{R T_{r e f}}-\ln \beta_{r e f} \\
\frac{1}{T_{\beta}}-\frac{1}{T_{r e f}}<R\left[\frac{\ln \left(\beta_{r e f} / \beta\right)}{E_{\alpha}}\right]
\end{gathered}
$$

then

$$
T_{r e f}-T_{\beta}<T_{\beta} T_{r e f} R\left[\frac{\ln \left(\beta_{r e f} / \beta\right)}{E_{\alpha}}\right]
$$

Under the condition of $\mathrm{d} \alpha / \mathrm{d} T_{\beta}>\mathrm{d} \alpha / \mathrm{d} T_{\text {ref }}, T_{\text {ref }}-T_{\beta}$ will increase. As the fractional extent of conversion $\alpha$ increases, $T_{\beta} T_{\text {ref }} R \ln \left(\beta_{\text {ref }} / \beta\right) / E_{\alpha}$ will continuously increase. It can be seen from eq (13) that $T_{\text {ref }}-T_{\beta}$ is not larger than $T_{\beta} T_{\text {ref }} R \ln \left(\beta_{\text {ref }} / \beta\right) / E_{\alpha}$. Therefore, eq (13) is logically reasonable. 
Based on the above discussion, it can be obtained that the reference offset $T_{\text {ref }}-T_{\beta}$ is not a constant. If the reaction is only kinetically controlled, the curves of $\alpha v s$. T should branch away from the master curve and the reference offset $T_{\text {ref }}-T_{\beta}$ will increase with the increase of $\alpha$. Additionally, in respect of some arbitrary $\alpha(0<\alpha<1)$, the reference offset $T_{\text {ref }}-T_{\beta}$ is not equal in $\mathrm{S}_{1}, \mathrm{~S}_{2}$ and $\mathrm{S}_{3}$ systems. The reason for $T_{\text {ref }}-T_{\beta}$ following the sequence $S_{1}>S_{2}>S_{3}$ may be ascribed to the degree of vitrification following the sequence $S_{3}>S_{2}>S_{1}$ at any of the heating rates considered. The filling of MWCNTs resulted in the increase of the degree of vitrification in the epoxy, especially at lower heating rate. Moreover, the cure reaction is more easily controlled by diffusion at larger $\alpha$, then the values of $\mathrm{d} \alpha / \mathrm{d} T_{\beta}$ decrease. Furthermore, TETA functional groups on the surface of chemically functionalized MWCNTs caused the increase of the degree of vitrification in the epoxy to some extent. This kind of influence of the TETA functional groups on the vitrification phenomena is complex. Consequently, a qualitative analysis of the degree of vitrification in $\mathrm{S}_{1}, \mathrm{~S}_{2}$ and $\mathrm{S}_{3}$ systems can be made through comparing the values of $T_{\text {ref }}-T_{\beta}$ from the curves in Figure 12(a)-(c). The filling of MWCNTs results in the increase of the degree of vitrification in the epoxy and the corresponding decrease of $\mathrm{d} \alpha / \mathrm{d} T_{\beta}$, which denotes that the cure reaction is inclined to be diffusion controlled at lower heating rate and larger degree of curing.

It is known that the activation energy represents the potential barrier and the mechanism of the cure reaction. Accordingly, the research on the activation energy is conducive to better understanding of the cure behaviors of MWCNT/ epoxy systems. The isoconversional method assumes that the activation energy is the function of the degree of curing. Two different isoconversional methods can be applied: the Friedman method (differential isoconversional method) and the Flynn-Wall-Ozawa method (integral isoconversional method). The activation energy obtained from the Flynn-WallOzawa method has been reported to be more reliable than that from the Friedman method. Moreover, the Flynn-Wall-Ozawa method reveals less sensitivity to noise than the Friedman method. ${ }^{33}$ In this work, we apply the Flynn-Wall-Ozawa method to calculate the activation energy of the cure reactions of $\mathrm{S}_{1}, \mathrm{~S}_{2}$ and $\mathrm{S}_{3}$ systems. This method is based upon eqs (14)-(15).

$$
\begin{gathered}
\ln \beta=\ln \left(\frac{A E_{\alpha}}{R}\right)-\ln g(\alpha)-5.331-1.052\left(\frac{E_{\alpha}}{R T}\right) \\
g(\alpha)=\int_{0}^{\alpha} \frac{\mathrm{d} \alpha}{f(\alpha)}
\end{gathered}
$$

where $\mathrm{g}(\alpha)$ is the integral conversion function.

As a result, the plot of $\ln \beta$ vs. $1 / T$ at the same $\alpha$ from a series of dynamic DSC thermograms at different heating rates would render a straight line where the slope allows the determination of the activation energy. Figure 13(a)-(c) exhibit Flynn-Wall-Ozawa plots of $\mathrm{S}_{1}, \mathrm{~S}_{2}$ and $\mathrm{S}_{3}$ systems for various values of $\alpha(\alpha=0.05,0.10,0.15,0.20, \ldots, 0.90,0.95)$. A good linear relationship can be seen from Flynn-Wall-Ozawa plots.
Values of $E_{\alpha}$ of $\mathrm{S}_{1}, \mathrm{~S}_{2}$ and $\mathrm{S}_{3}$ systems obtained for each value of $\alpha$ are shown in Figure 14. The dependence of the activation energy of $S_{1}, S_{2}$ and $S_{3}$ systems as a function of degree of curing was observed. Trying various multiple regression equations to fit the values of $E_{\alpha}$, we found that cubic polynomial can have enough goodness of fit, that is, if highorder moments are used to fit the values of $E_{\alpha}$, the coefficient of the items whose numbers of order are greater than or equal to 4 in the polynomial expressions will be smaller than $10^{-5}$. Consequently, cubic polynomial is good enough to fit the values of $E_{\alpha}$. The fitted multiple regression equations for values of $E_{\alpha}$ of $\mathrm{S}_{1}, \mathrm{~S}_{2}$ and $\mathrm{S}_{3}$ systems can be separately expressed in eqs (16), (18) and (20).

$\mathrm{S}_{1}$ system:

$$
\begin{aligned}
E(\alpha)= & 69.80026-35.79507 \alpha \\
& +74.85288 \alpha^{2}-72.30322 \alpha^{3} \quad \alpha \in(0,1) \\
\mathrm{d} E / \mathrm{d} \alpha= & -35.79507+149.70576 \alpha-216.90966 \alpha^{2}<0
\end{aligned}
$$

$\mathrm{S}_{2}$ system:

$$
\begin{aligned}
E(\alpha)= & 70.33147-10.78226 \alpha \\
& +6.99794 \alpha^{2}-15.68283 \alpha^{3} \quad \alpha \in(0,1) \\
\mathrm{d} E / \mathrm{d} \alpha= & -10.78226+13.99588 \alpha^{2}-47.04849 \alpha^{3}<0
\end{aligned}
$$

$\mathrm{S}_{3}$ system:

$$
\begin{aligned}
E(\alpha)= & 70.29673-13.10851 \alpha \\
& +4.76735 \alpha^{2}-18.77349 \alpha^{3} \quad \alpha \in(0,1) \\
\mathrm{d} E / \mathrm{d} \alpha= & -13.10851+9.5347 \alpha+56.32047 \alpha^{2}<0
\end{aligned}
$$

It can be seen from Figure 14 that the values of $E_{\alpha}$ of $\mathrm{S}_{1}, \mathrm{~S}_{2}$ and $\mathrm{S}_{3}$ systems decrease with increasing $\alpha$, which can be further proved by the fact that with regard to $S_{1}, S_{2}$ and $S_{3}$ systems, the differential equation of $E(\alpha)$, that is, $\mathrm{d} E / \mathrm{d} \alpha$, is smaller than zero, which indicates that $E(\alpha)$ is a decreasing function. The corresponding expressions of $\mathrm{d} E / \mathrm{d} \alpha$ are presented in eqs (17), (19) and (21). In terms of the above discussion, the filling of unmodified and chemically modified MWCNTs does not change the cure reaction mechanism of epoxy; namely, the process of cure is still autocatalytic. The first step in the cure reaction of DGEBA/EMI-2,4 system is the formation of both $1: 1$ and 2:1 adducts. ${ }^{30}$ The 2:1 adduct, which contains the nucleophilic alkoxide ion, was regarded as the catalyst that activated the etherification reaction. Moreover, the number of the 2:1 adduct does not reduce because the alkoxide ion is continuously regenerated during the etherification reaction. Based on the fact that the heat of cure is mainly generated from the etherification reaction, it is reasonable to expect a decrease in $E_{\alpha}$ of MWCNT/DGEBA/EMI-2,4 system. In addition, the phenomena for $E_{\alpha}$ following the sequence $S_{2}>S_{1}$ and $S_{3}>S_{1}$ may be attributed to the retardation effect caused by MWCNTs on the cure reactions of epoxy. This kind of the inhibition effect enhances potential barrier of the cure reaction, so the activation energy is increased. Furthermore, the reason for $E_{\alpha}$ following the sequence $\mathrm{S}_{3}<\mathrm{S}_{2}$ may be ascribed to the role of TETA functional groups on the chemically modified MWCNT surface. These TETA functional groups promote the primary 

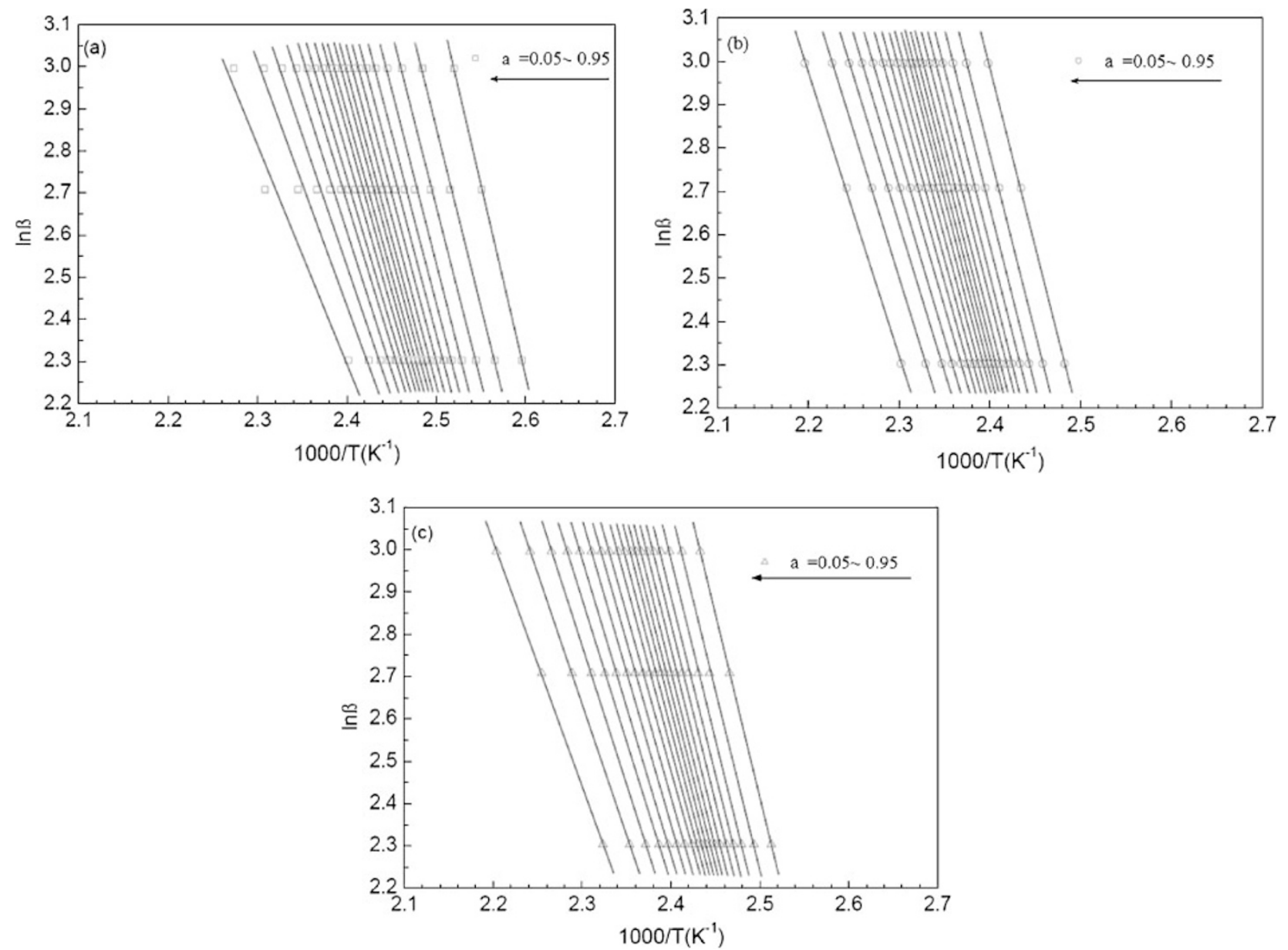

Figure 13. Flynn-Wall-Ozawa plots at various degrees of curing of $S_{1}, S_{2}$ and $S_{3}$ systems. (a) $S_{1}$; (b) $S_{2}$; (c) $S_{3}$.

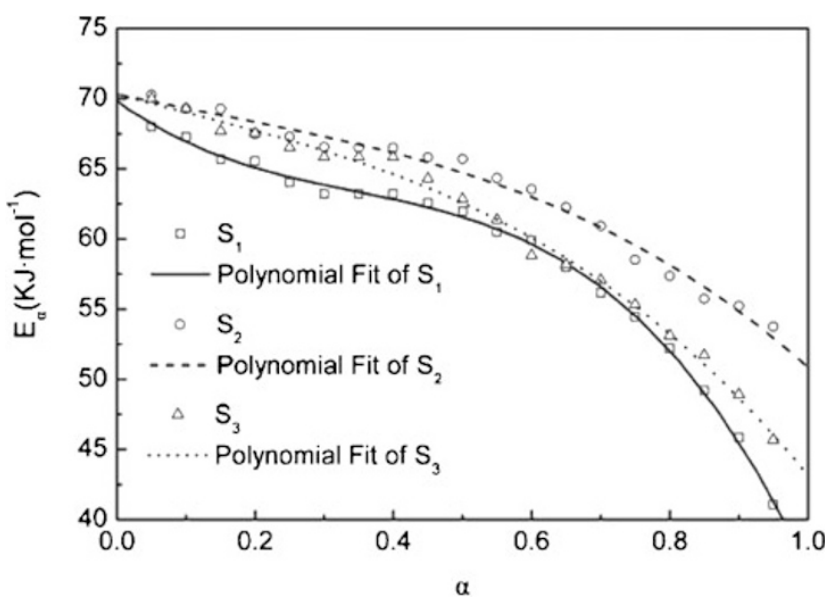

Figure 14. Values of the activation energy of $S_{1}, S_{2}$ and $S_{3}$ systems obtained from Flynn-Wall-Ozawa plots at different $\alpha$.

amine-epoxide reaction and efficiently weaken the retarding effect caused by MWCNTs on the cure reaction, which contributes to the lowering of potential barrier of cure and the corresponding decrease of the activation energy.

\section{CONCLUSIONS}

In this work, TETA grafting of MWCNTs was carried out. XPS and Raman analyses show the effectiveness of chemical functionalization of MWCNTs. HRTEM analysis indicates that TETA is grafted onto the MWCNT surface to form a thin layer. FESEM images denote that TETA grafting varies the forces among MWCNTs from polar to nonpolar, thus big agglomerates of acid-treated MWCNTs are broken and the loose state is recovered. The interspaces formed in TETA-grafted MWCNTs are larger, which is beneficial to their better dispersion in epoxy matrix. Cure behavior of MWCNT/epoxy system and the effect of chemical functionalization of MWCNTs on the cure reaction were studied. In the dynamic DSC experiments, the heat of cure is nearly independent of the heating rate. The filling of unmodified and chemically modified MWCNTs does not change the cure reaction mechanism of epoxy, while MWCNTs delay the cure reaction because of their steric hindrance. TETA functional groups on the chemically functionalized MWCNT surface can act as curing agents and facilitate the primary amine-epoxide reaction, which means that they weaken the retardation effect caused by MWCNTs on the cure reaction of epoxy. The phenomena for $T_{\mathrm{i}}, T_{\mathrm{p}}$ and $E_{\alpha}$ 
following the sequence $S_{2}>S_{3}>S_{1}$ may be attributed to the combined effects of MWCNTs and TETA functional groups on the cure reactions. Additionally, the filling of MWCNTs causes the continuous increase of the degree of vitrification in the epoxy system and the corresponding decrease of $\mathrm{d} \alpha / \mathrm{d} T_{\beta}$, which denotes that the cure reaction is prone to be diffusion controlled at lower heating rate and larger degree of curing.

Acknowledgment. The authors are grateful to Instrumental Analysis Centre of Shanghai Jiao Tong University for providing the support for this work.

Received: March 18, 2009

Accepted: May 28, 2009

Published: July 15, 2009

\section{REFERENCES}

1. S. Iijima, Nature, 354, 56 (1991).

2. A. K. T. Lau and D. Hui, Composites Part B, 33, 263 (2002).

3. Z. Ounaies, C. Park, K. E. Wise, E. J. Siochi, and J. S. Harrison, Compos. Sci. Technol., 63, 1637 (2003).

4. M. J. Biercuk, M. C. Llaguno, M. Radosvljevic, J. K. Hyun, and A. T. Johnson, Appl. Phys. Lett., 80, 2767 (2002).

5. H. Geng, R. Rosen, B. Zheng, H. Shimoda, L. Fleming, and J. Liu, Adv. Mater., 14, 1387 (2002).

6. Y. J. Kim, T. S. Shin, H. D. Choi, J. H. Kwon, Y.-C. Chung, and H. G. Yoon, Carbon, 43, 23 (2005).

7. Y. S. Song and J. R. Youn, Carbon, 44, 710 (2006).

8. W. Tang, M. H. Santare, and S. G. Advani, Carbon, 41, 2779 (2003).

9. S. J. Park, M. S. Cho, S. T. Lim, H. J. Cho, and M. S. Jhon, Macromol. Rapid Commun., 24, 1070 (2003).

10. S. Mondal, Man-Made Text. India, 46, 329 (2003).

11. K. Liao and S. Li, Appl. Phys. Lett., 79, 4225 (2001).

12. C. A. Mitchell, J. L. Bahr, S. Arepalli, J. M. Tour, and R. Krishnamoorti, Macromolecules, 35, 8825 (2002).
13. W. D. Zhang, L. Shen, I. Y. Phan, and T. Liu, Macromolecules, 37, 256 (2004).

14. T. Liu, I. Y. Phang, L. Shen, S. Y. Chow, and W.-D. Zhang, Macromolecules, 37, 7214 (2004).

15. D. Gan and L. A. Lyon, Macromolecules, 35, 9634 (2002).

16. A. Moisala, Q. Li, I. A. Kinloch, and A. H. Windle, Compos. Sci. Technol., 66, 1285 (2006).

17. A. Bagchi and S. Nomura, Compos. Sci. Technol., 66, 1703 (2006).

18. Y. Ando, X. Zhao, H. Shimoyama, G. Sakai, and K. Kaneto, Int. J. Inorg. Mater., 1, 77 (1999).

19. F. H. Gojny, M. H. G. Wichmann, B. Fiedler, I. A. Kinloch, W. Bauhofer, and A. H. Windle, Polymer, 47, 2036 (2006).

20. D. Rosu, A. Mititelu, and C. N. Cascaval, Polym. Test., 23, 209 (2004).

21. D. Rosu, C. N. Cascaval, F. Mustata, and C. Ciobanu, Thermochim. Acta, 383, 119 (2002).

22. D. Puglia, L. Valentini, I. Armentano, and J. M. Kenny, Diamond Relat. Mater., 12, 827 (2003).

23. J. Bae, J. Jang, and S.-H. Yoon, Macromol. Chem. Phys., 203, 2196 (2002).

24. D. Puglia, L. Valentini, and J. M. Kenny, J. Appl. Polym. Sci., 88, 452 (2003).

25. T. Zhou, M. Gu, Y. Jin, and J. Wang, J. Polym. Sci., Part A: Polym. Chem., 44, 371 (2006).

26. G. Zhang, S. Sun, D. Yang, J.-P. Dodelet, and E. Sacher, Carbon, 46, 196 (2008).

27. K. Papagelis, M. Kalyva, D. Tasis, J. Parthenios, A. Siokou, and C. Galiotis, Phys. Status Solidi B, 244, 4046 (2007).

28. H.-X. Wu, R. Tong, X.-Q. Qiu, H.-F. Yang, Y.-H. Lin, and R.-F. Cai, Carbon, 45, 152 (2007).

29. H.-X. Wu, X.-Q. Qiu, W.-M. Cao, Y.-H. Lin, R.-F. Cai, and S.-X. Qian, Carbon, 45, 2866 (2007).

30. T. Zhou, M. Gu, Y. Jin, and J. Wang, Polym. J., 37, 833 (2005).

31. Z. Fang, J. Wang, A. Gu, and L. Tong, Front. Mater. Sci. Chin., 1, 415 (2007).

32. N. Sbirrazzuoli and S. Vyazovkin, Thermochim. Acta, 388, 289 (2002).

33. C. Jubsilp, S. Damrongsakkul, T. Takeichi, and S. Rimdusit, Thermochim. Acta, 447, 131 (2006). 